\title{
La educación de párvulos y la misión pedagógica: un contacto cultural entre México y Estados Unidos, 1883-1910
}

Kindergarten and the Pedagogical Mission: A Cultural Contact Between Mexico and the United States, 1883-1910

Educação pré-escolar e missão pedagógica: um contato cultural entre o México e os Estados Unidos, 1883-1910

\section{Lucía Martínez-Moctezuma* (iD orcid.org/0000-0002-4957-6989}

Para citar este artículo: Martínez-Moctezuma, L. (2021). La educación de párvulos y la misión pedagógica: un contacto cultural entre México y Estados Unidos, 1883-1910. Revista Colombiana de Educación, 1(82), 281-300. https://doi.org/10.17227/rce.num82-11119

\section{(c). (i) (8)}

Recibido: 31/12/2019

Evaluado: 02/08/2020

$12 / 08 / 2020$

* Instituto de Ciencias de la Educación. Universidad Autónoma del Estado de Morelos. México. 


\section{Resumen}

En este artículo, producto de una investigación más amplia, se analiza la adopción de una propuesta pedagógica para el sistema escolar mexicano en la educación de párvulos. Vista desde la perspectiva histórica, donde la misión pedagógica, se convierte en una estrategia para conocer el sistema escolar que circula desde finales del siglo xix en Europa y del que aprenderán las profesoras mexicanas por la mediación del sistema escolar norteamericano. Becadas para visitar diversos establecimientos escolares en los Estados Unidos, un grupo de profesoras cobrará visibilidad en un medio primordialmente masculino, gracias a sus informes, y sus escritos publicados en revistas pedagógicas y, libros escolares, así como en la práctica y a su ejercicio como profesoras y directoras, dirigiendo grupos o creando escuelas. En esta investigación se analizan además los reportes de sus visitas a las escuelas, sus expedientes personales, así como diversos artículos redactados y publicados en revistas pedagógicas de la época en las que se incluye la fotografía como una fuente de información.

\section{Palabras clave}

Kindergarten; educación infantil; estudios en el extranjero; métodos educativos; educación de la mujer
Keywords

Kindergarten; early childhood education; study abroad; educational methods; women education.

\begin{abstract}
This article, result of a wider research, analyzes the adoption of a pedagogical proposal for the Mexican school system: kindergarten. Seen from the historical perspective, the pedagogical mission becomes a strategy to know the school system that has been circulating since the end of the 19th century in Europe and from which Mexican teachers will learn through the mediation of the North American school system. With multiple scholarships to visit various schools in the United States, a group of teachers will gain visibility in a primarily male environment, thanks to their reports and their writings published in pedagogical journals, schoolbooks as well as in practice as teachers and principals, directing groups or Creating schools. The research analyzes the reports of their visits to schools, their personal files as well as various articles written and published in pedagogical journals of the time, in which photography is included as a source of information.
\end{abstract}

\section{Resumo}

Este artigo de pesquisa analisa a adoção de uma proposta pedagógica para o sistema escolar mexicano: a educação pré-escolar. Vista da perspectiva histórica, a missão pedagógica torna-se uma estratégia para conhecer o sistema escolar que circula desde o final do século xix na Europa e a partir do qual as professoras mexicanas aprenderão através da mediação do sistema escolar norte-americano. Com bolsas de estudo para visitar várias escolas nos Estados Unidos, um grupo de professoras ganhará visibilidade em um ambiente basicamente masculino, graças aos seus relatórios e escritos publicados em revistas pedagógicas, livros escolares e na prática como professoras e diretoras, liderando grupos ou criando escolas. A pesquisa analisa os relatórios de suas visitas às escolas, seus arquivos pessoais e vários artigos escritos e publicados em revistas pedagógicas da época em que a fotografia é incluída como fonte de informação.

\section{Palavras-chave}

Educação infantil; educação pré-escolar; estudos no estrangeiro; métodos educativos; educação da mulher 


\section{Introducción}

En este trabajo se subraya la importancia que ha tenido el contacto cultural entre México y Estados Unidos durante el periodo presidencial de Porfirio Díaz (1876-1910)' , en el que se ofrecieron becas para que el magisterio viajara con el fin de aprender los nuevos saberes y los sistemas que se discutían en el panorama escolar internacional. Matasci $(2012 ; 2015)$ ha señalado la importancia de la misión pedagógica como una estrategia para comprender cómo se articula un régimen circulatorio de intercambios, de contactos y de conexiones multidireccionales orientados a la construcción y a la integración de nuevas ideas en los debates nacionales en un momento de construcción de los Estados-Nación. La afirmación de este modelo durante el siglo xix impuso el espacio nacional como el marco de referencia dominante, donde la escuela se convirtió en un medio para fijar la nación contribuyendo a su materialidad, a su invención y a su perennidad. Es el momento de "la primera globalización", en el que se establecen intercambios y se intensifican conexiones entre países (Matasci, 2012), donde la escuela constituye la cuna de la ciudadanía política propia de cada país y el manual escolar uno de los vectores mayores en la construcción identitaria de los pueblos (Matasci, 2015).

A pesar de su importancia, el tema de la misión pedagógica ha sido poco explorado en la historiografía de la educación, de los pocos trabajos que existen me interesa resaltar cuatro que proponen varias líneas de reflexión. Para el caso brasileño, el trabajo coordinado por José Goncalves Gondra y Ana Chrystina Venancio Mignot (2007) subraya la importancia de los educadores en la circulación de los modelos pedagógicos y el diálogo transnacional entre Europa y Brasil, desde finales del siglo xIx y los primeras años del xx como un proceso de confirmación de la escuela moderna. Para el caso europeo la obra de Rebecca Rogers y Damiano Matasci resultan capitales porque han planteado el valor del viaje pedagógico en la construcción del sistema educativo de países que, como México, se encontraban constituyéndose como un Estado-Nación. Para el caso mexicano, el texto coordinado por Galván et ál. (2014) muestra el posicionamiento de las profesoras en diferentes espacios como el sindicato, la escuela católica y la escuela rural, donde la escritura desempeñó un papel importante para develar su presencia.

1 Porfirio Díaz (Oaxaca de Juárez, México, 1830-París, Francia, 1915) gobernó el país desde 1876 hasta 1911, año en que inició la Revolución mexicana. En este periodo se estimuló la realización de congresos educativos en el que se acordó el desarrollo de la educación mixta, la enseñanza simultánea, el uso del procedimiento intuitivo en la clase, la formación de maestros, la publicación de libros de texto escritos por autores nacionales y la formación femenina que transformaron el medio educativo urbano. 
En lo que respecta a la formación del magisterio especializado en la educación de párvulos, se dice haber omitido el estudio de la mayor parte de las profesoras normalistas del siglo xix para privilegiar el de una élite formada por profesoras como Rosaura Zapata, Estefanía Castañeda y Bertha Von Glumer (González, 2008); no obstante, en realidad no existe tal avance porque se desconoce hasta ahora cómo estas profesoras conocieron la formación de párvulos en sus viajes al extranjero y cómo adaptaron estos saberes a la escuela mexicana proponiendo su discusión en los espacios adecuados para integrar esta formación al currículo nacional. Es por esta razón que los artículos de Bazant $(2003 ; 2013)$ resultan una excepción, pues se trata de uno de los primeros textos que ha explorado el tema de las maestras viajera, tomando como ejemplo el expediente de Laura Méndez de Cuenca sobre su visita a San Luis, Misuri, localizado en el Archivo Histórico de la Secretaría de Educación, donde va articulando los rasgos de su personalidad.

Para plantear el problema de las misiones pedagógicas se exploran dos fuentes de información de la época que, a mi parecer, son imprescindibles: las revistas pedagógicas y los informes clasificados en la Sección Personal Sobresaliente del Archivo Histórico de la Secretaría de Educación Pública, algunos de estos publicados, por entregas, en las revistas pedagógicas. La claridad y la calidad de los comentarios a veces tan detallados confirma la idea de Frank Simon quien clasifica a la prensa pedagógica como la madre de todas las fuentes, fundamental para el análisis de los problemas educativos de finales del siglo xIx y principios del xx, en un momento en el que los países se constituyen como Estados-Nación (Braster y Del Pozo, 2018). Como en otros países, en México, la prensa estimuló la circulación, la construcción y la integración de nuevas ideas a los debates sobre la escuela en las que fue importante el componente extranjero para diseñar el plan de estudios del nuevo ciudadano. Discursos en los que el investigador puede seguir la auténtica normalidad, a través de la normatividad de la fuente (Barby et ál., 2016).

Es en esta línea donde se inserta esta propuesta en la que se busca reflexionar en torno a la idea que ha planteado Hussaye sobre la importación pedagógica para entender cómo se opera el diálogo entre el pedagogo y las pedagogías, donde la importación-exportación de estas pedagogías dejó de lado la idea tradicional en la que se situaba a un pedagogo inerte, influido por el movimiento pedagógico pero sin mostrar una reacción (Rogers, 2008). Un diálogo que se observa en el caso mexicano donde las profesoras seleccionado para realizar misiones pedagógicas logra difundir y poner en práctica, a partir de sus escritos, las ideas sobre la educación de párvulos o kindergarten, en una época en la que el medio escolar estaba dominado por un grupo de profesores y hombres de poder. El interés se centra en saber cómo se instrumenta la experiencia adquirida por estas 
profesoras quienes van construyendo un conocimiento, teórico y práctico, durante sus misiones pedagógicas y van adaptándolo al medio escolar mexicano. En sus discursos es posible identificar métodos y teorías pedagógicas pero también se develan sus redes de sociabilidad, su conocimiento y su práctica que las convierte en elementos activos al instrumentar un conocimiento nuevo en la escuela

En un primer apartado plantearé el contexto en que se desarrollan las escuelas de párvulos en México, posteriormente analizaré los informes de dos profesoras mexicanas que cumplieron misiones pedagógicas en los Estados Unidos.

\section{La escuela de párvulos en México}

Las primeras escuelas de párvulos en México fueron fundadas por Enrique Laubscher, en Veracruz (1883) y Manuel Cervantes Imaz en la Ciudad de México (1884). La escuela veracruzana formó parte de un plan integral con la inauguración de una escuela modelo en la Academia Normal porque Laubscher había sido discípulo de Froebel y contaba con el apoyo del director Enrique Rébsamen, también suizo y afincado en México desde $1880^{2}$. El profesor Rébsamen, puso en práctica la enseñanza objetiva en el país, desarrolló un plan de estudios basado en las ideas de Pestalozzi, Froebel y Herbart para implementar un sistema especial, el kindergarten, como lo había definido Froebel (Bazant, 2013).

Fue hasta 1890 que hubo intentos por reglamentar esta enseñanza. El regidor comisionado de Instrucción Pública en el Ayuntamiento de la ciudad de México reunió una junta con objeto de reglamentar y uniformar las escuelas municipales de párvulos donde se tomaron los primeros acuerdos: los ejercicios serían educativos con el fin de atender al desarrollo armónico de las facultades físicas, intelectuales y morales de los niños; la escuela de párvulos era educativa no instructiva y eran, las directoras, quienes basándose en su desarrollo determinarían el momento en el que el niño debía pasar a la escuela elemental.

2 Enrique Conrado Rébsamen Egloff (Suiza, 1857-Ciudad de México, 1904) transformó el sistema escolar mexicano de finales del siglo xIx. Durante el Segundo Congreso de Instrucción Pública de 1889, estimula las discusiones entre los profesores, en las que introduce las ideas de autores franceses, como Ferdinand Buisson o Compayre, y plantea problemas que se discuten en el medio europeo como la educación mixta, la formación femenina, la realización de paseos escolares. Una muestra de sus preocupaciones se refleja en el contenido de su biblioteca localizada hoy en la Escuela Normal de Xalapa en Veracruz (México), donde existen colecciones completas de la Revue de Pedagogie, o libros de texto como los de Ernest Lavisse y G. Bruno, grandes éxitos de la escuela primaria francesa. 
Las escuelas municipales no tuvieron los resultados esperados porque no se aproximaban a "las tendencias de la pedagogía moderna" (Ayuntamiento de la Ciudad de México, 1900, pp. 300-304) , por esta razón, durante el Segundo Congreso de Instrucción Pública (1890) se constituyó una comisión especial para discutir tres cuestiones que tenían que ver con este nivel de estudios: la edad a la que debían ingresar los niños, la necesidad de un programa de estudios y el cuestionamiento para excluir la enseñanza de la lectura y la escritura en este nivel de estudios. Como respuesta a esta convocatoria, algunas entidades iniciaron su enseñanza: en el Estado de Jalisco se atendió la educación de niños y niñas de cuatro a seis años, con un programa que incluía juegos libres y gimnásticos, Dones de Froebel y trabajos manuales cuyo objetivo era el desarrollo físico, intelectual y moral. En el Estado de Morelos la formación de párvulos atendió a los menores de siete años que pudieran expresarse claramente (Jalisco, 1900). La única escuela dependía de la Secretaría de Gobierno y estaba atendida por una directora, tres ayudantes y tres auxiliares. El programa era el mismo que se impartía en la escuela anexa a la Normal de la ciudad de México y cumplía el año escolar de enero a octubre (Morelos, 1900).

Como observamos en estos ejemplos, el nivel escolar no estaba aún definido, por esta razón, se implementaron las misiones pedagógicas para conocer y difundir sobre este y otros saberes en el medio escolar ${ }^{3}$. No se trataba de copiar ciegamente la legislación escolar del país que se visitaba sino estudiar la escuela como pedagogo y observar, comparar, elegir para luego implementar lo aprendido, de esta manera debían guiarse, así lo señalaba el director de la Escuela Normal de la Ciudad de México, Alberto Correa, pues era la pedagogía la que se aplicaba en la dirección del niño de kindergarten y la escuela elemental, un arte que servía para educar al niño física, moral e intelectualmente (Correa, 1906).

Se organizaron entonces diferentes grupos que viajaron al extranjero para conocer los avances pedagógicos. En 1904, Emilio Rabasa quien era director de la Escuela de Artes y Oficios, fue enviado a Nueva York para estudiar sobre el trabajo manual. La maestra Teresa Guerrero, directora de la Escuela Comercial Lerdo, fue pensionada por el gobierno de los Estados Unidos junto con el médico Luis E. Ruiz para estudiar la organización de las escuelas primarias.

3 Tampoco estaban definidas las características de este grupo. Pedro Canales (2019) ha señalado que en los registros parroquiales durante la época colonial, se observa cómo cada cura sigue su propia lógica y, por tanto, varía la edad de los párvulos. Hay una tendencia entre los párrocos quienes anotan la edad junto al calificativo de párvulo, el límite mayor es 12 años para los niños y frecuentemente diez para las niñas, edad que coincide con el fin de la etapa de maduración del timo (uno de los dos órganos maestros del sistema inmunitario). A principios de siglo XIX (1824-1826) ha encontrado parroquias donde asientan regularmente la edad $y$, a veces, ya se les menciona como adultos con 8 años. 
En 1905, las profesoras Raquel Santoyo y Carmen Krause de la Rosa fueron comisionadas durante quince días para visistar, The Chicago Normal School, The Univesity School of Education, The Lewis Institute, The Metropolitan Bussines College y subrayaron la existencia de 173 escuelas normales, en las que se preparaba a las maestras de kindergarten. En el Lewis Institute, por ejemplo, observaron la enseñanza de la economía doméstica, la educación Industrial y visitaron la Exposición Internacional de San Luis, Misuri, para conocer el funcionamiento de las escuelas comerciales e industriales. En esa misma exposición encontraron que los trabajos del kindergarten había que mirarlos con un esfuerzo de imaginación aunque resaltaban el valor del manual training o adiestramiento manual, como se le llamaba en la época. Posteriormente viajaron a Chicago donde las recibió la Sra. Olive E.weston para visitar una serie de asociaciones que gastaban cerca de un millón de dólares al año en instituciones escolares, bibliotecas circulantes y museos.

El profesor Manuel Velázquez Andrade se encargó de informar sobre la enseñanza de la educación física y posteriormente viajó a Estocolmo para comparar sus impresiones; también observó la enseñanza del dibujo en las escuelas de Chicago y San Francisco (Velásquez, 1905). Hacia Europa viajó la maestra Dolores Correa Zapata quien visitó una escuela de niñas, un kindergarten y una escuela Normal en Berlín. En 1906 Clementina Ostos, inspectora de Enseñanza Normal y el ingeniero Félix F. Palavicini, profesor de Trabajos Manuales en la Escuela Práctica Anexa a la Normal de Profesores de la Ciudad de México viajaron a Europa para estudiar el funcionamiento de las escuelas Primarias Industriales de Alemania, Francia y Bélgica.

Como vemos había un buen grupo que había viajado al extranjero para conocer sobre diferentes saberes escolares, por esta razón, en 1907 la Academia de Profesores solicitó la lectura de sus informes y la publicación de monografías pedagógicas que pudieran ser de utilidad para aclarar diversos puntos de la pedagogía (Academia de Profesores, 1907). Al cabo de unos años, la práctica dio origen a la ley de 1908 para enviar al extranjero maestros aptos, a efecto de que hicieran los estudios que se les prescribían (Galván, 1991). El ministro de Instrucción Pública, Ezequiel Chávez, esperaba que los profesores comisionados a Europa y a los Estados Unidos de América estuvieran listos para procesar las impresiones, ideas y sentimientos que les despertaran estos viajes, de tal manera que a su regreso fueran capaces de ponerlos en práctica siguiendo la consigna de estudiar a la escuela como pedagogo para observar cómo la sociedad y la escuela influían en el país (Chávez, 1904) ${ }^{4}$.

4 Ezequiel Chávez fue secretario de Justicia e Instrucción Pública de 1895 a 1900 y subsecretario de Instrucción Pública y Bellas Artes de 1905 a 1911. En 1903 realizó una misión pedagógica hacia los Estados Unidos para estudiar la creación de la Universidad Nacional. Compuso canciones para niños.

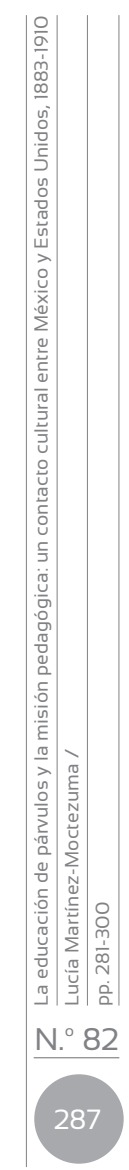




\section{Rosaura Zapata y Laura Méndez de Cuenca, dos profesoras viajeras}

A partir de la lectura de las fuentes coincidimos con la tipología que se plantea para el caso español: los viajeros son hombres y mujeres del medio urbano, con estudios normalistas, buen nivel social y aunque no hay seguridad, en todos los casos, con el dominio de la lengua del país al que viajaban, eran maestros en activo, algunos escribieron libros de texto; otros dirigieron escuelas, como directores e inspectores y en ellas pusieron en práctica lo aprendido; ninguno sufragó el viaje con sus medios y todos escribieron largos informes que entregaron primero al ministerio de Educación y posteriormente se publicaron en revistas pedagógicas que despertaron el interés de sus lectores (Moreno, 2007).

En el caso de las maestras mexicanas fue notable su contribución a la renovación pedagógica del país. Como en el caso de otras viajeras europeas, se trataba de profesoras inquietas y profesionales que ejercieron una función de mediación entre la recepción de nuevas corrientes pedagógicas, su introducción, su adaptación y su difusión en la escuela mexicana. Formaban un grupo de nuevas profesoras que buscaron de manera imaginativa conciliar la teoría y la práctica dirigiendo las primeras escuelas de párvulos en México (Rogers, 2008).

Como vimos en el apartado anterior, entre 1903 y 1908 se multiplicaron las comisiones, en el caso de Rosaura Zapata y Laura Méndez de Cuenca su misión consistió en registrar sus impresiones sobre los establecimientos modelo de párvulos norteamericanos ${ }^{5}$. La profesora Rosaura Zapata (La Paz, Baja California Sur, 1876 y Ciudad de México, 1963) fue la hija de un militar, hizo estudios normalistas y adquirió experiencia en el medio, primero como ayudante y después como profesora. En 1903, fue becada por el Gobierno mexicano para conocer el sistema de educación utilizado en el kindergarten en San Francisco, Boston y Nueva York, en los Estados Unidos. Viajó en compañía de su hermana Elena y le fueron asignados 500 pesos para sus gastos y sus traslados (AHSEP, Expediente de Rosaura Zapata, 1898-1945). En ese momento, en México no existía una escuela donde se formaran estas maestras, así que el aprendizaje en el extranjero, unido al conocimientos de otras profesoras como Estefanía Castañeda y Bertha von Glumer, permitió que en la Ley Constitutiva de las Escuelas Normales Primarias se consignara la carrera de educadora de párvulos desde 1909 (Zapata, 1908).

5 Mílada Bazant ha explorado el tema de la maestra viajera tomando como ejemplo el caso de la profesora Laura Méndez de Cuenca. Consultó el expediente sobre su visita a San Luis, Misuri, localizado en el Archivo Histórico de la Secretaría de Educación plantea los rasgos de su personalidad y su conocimiento sobre el sistema escolar (Bazant, 2013 y 2003). 
En 1908, Rosaura Zapata viajó a Europa para profundizar sus conocimientos en el sistema Froebel consultando los programas y asistiendo a clases para conocer el método y en Inglaterra visitó las escuelas al aire libre para niños anémicos (Galván, 1991). Su vida profesional se amplió a otras actividades: en 1927, se inscribió en la Facultad de Filosofía y Letras y en la Escuela Normal Superior, donde recibe cursos de Psicología Educativa, Educación, Psicología General y Especial, Organización y Administración Escolar. En 1942 asistió al Congreso Panamericano del Niño en la ciudad de Washington y se jubiló después de cincuenta años de labor dedicada al magisterio (AHSEP, Expediente de Rosaura Zapata, 1898-1945).

Laura Méndez de Cuenca, por su parte, laboró 42 años en la educación pública como profesora, inspectora y como miembro de diversas comisiones como la del Consejo Superior que era el máximo órgano en la materia. Además del magisterio, incursionó en la poesía, el cuento y la novela. La profesora Méndez recibió del cónsul mexicano en Estados Unidos, un salario de 50 dólares (100 pesos mexicanos) para realizar una misión pedagógica por las escuelas de San Luis, Misuri entre 1902 y 1904. Una experiencia que compararía con la alemana consultada en la bibliografía a la que tenía acceso y que conocería personalmente hasta $1907^{6}$.

Alberto Correa, director general de la Enseñanza Normal, director de la revista La Enseñanza Normal y para muchos el impulsor de las misiones pedagógicas consideraba que si la escuela era la generadora de todo progreso entonces era el misionero pedagógico quien debía responder a la necesidad de abrir los horizontes:

paseando atentamente la mirada por diversos campos de la enseñanza, aspirando el ambiente que en ellos domina, oyendo con cuidado los latidos de cada organismo escolar [...] tactar con prudencia [para] tener profundo conocimiento del sistema educacional de otras naciones y estableciendo paralelos, haciendo comparaciones, buscando causas y efectos, analizando, deduciendo, sabrá que puede aplicarse a nuestra anemia lo que se receta para países pletóricos de vida [...] todo cuanto constituye el alma de la educación radica en el Maestro, y es preciso que con él se pongan en íntimo contacto los maestros de nuestra patria, que el Gobierno envía al extranjero.

Los libros de pedagogía y la legislación escolar de otras naciones no bastaban para comprender cómo enseñaba el maestro y cómo enfrentaba las facilidades o las resistencias de la escuela y el medio social. La teoría servía de mucho pero era la práctica donde se ponían en juego los conocimientos. Ya lo sentenciaba Alberto Correa, "los viajes ilustran y despiertan las facultades de los hombres al mostrarles en cada país,

6 Un apoyo limitado si se compara con su salario de 25 pesos mensuales como maestra y 150 pesos como inspectora (Bazant, 2003). 
sus progresos en las ciencias y en las artes, cada pueblo, sus particularidades, la raza, sus costumbres por esta razón era necesario que los maestros viajaran para conocer y si esto no era posible pues entonces comisionar a un grupo de los mejores quienes regresarían y difundirían sus aprendizajes a través de informes, reportes, libros, enseñanzas [...] este es el secreto de nuestro porvenir, del porvenir de la patria" (Correa, 1906, p. 89).

\section{Los informes de las misiones pedagógicas en Estados Unidos}

Las exploraciones pedagógicas alimentan una producción de saberes sobre el extranjero que manejan una visión diferente del contexto escolar nacional y estimulan una reflexión posible únicamente a través de la comparación con otras experiencias. Los viajes son exclusivos de un público de especialistas y de expertos que buscan en el país extranjero un repertorio de ejemplos aptos para aclarar las políticas o las reformas escolares en su propio país. En sus discursos es posible identificar los elementos que ejercen fascinación, a saber, la diversidad de métodos y de teorías pedagógicas, la introducción de la obligación y de la gratuidad escolar, así como el desarrollo de las instituciones profesionales. Se trata, como dice Matasci, de una serie de representaciones idealizadas que no reflejan necesariamente la realidad histórica que es evidentemente mucho más compleja pero que permiten observar el impacto de los fenómenos educativos así como el uso de la referencia extranjera en el proceso de la adopción de una reforma escolar (Matasci, 2012).

En este marco general, observamos los informes de las profesoras Rosaura Zapata y Laura Méndez de Cuenca. Dos informes que en lo general son similares porque observan puntos en común pero que en lo particular tienen el sello de cada informante; en el caso de Laura Méndez, escrito con espíritu crítico y comparativo que confirma lo que señalaba Frank Simon, como una característica valiosa de la fuente misma (Barby et ál., 2016; Braster et ál., 2018).

Por la intermediación del cónsul mexicano en Nueva York, Rosaura Zapata visitó el Instituto Froebel, una institución dedicada a la formación y la práctica de las maestras que se ocuparían de la enseñanza en el kínder. En primer lugar, describió el edificio: dos plantas, la baja reservada para la educación de los niños, la biblioteca y el despacho de la directora; y la alta, usada para impartir las clases de gimnasia, trabajos manuales y estudio de la naturaleza. Llamaba su atención el hecho de que el edificio estuviera rodeado por un jardín con árboles, plantas y flores, en labores que compartían los alumnos y las futuras maestras que ahí estudiaban. 
Este mismo jardín servía para separar el primer edificio de un segundo en el cual se daba clase a alumnos que tenían alguna anormalidad y donde también se les preparaba con el sistema Froebel.

En cuanto a los edificios que visitó en San Luis, Misuri, la profesora Méndez señaló el hecho de que ningún maestro, director o conserje habitaba en la escuela y eso no era motivo de inasistencia o impuntualidad, como en el caso mexicano, pues se presentaban media hora antes de que iniciaran las clases. En la planta baja se ubicaba la Dirección, una o dos salas para párvulos del primer grado, y de tres a cinco salas para los siguientes grados. Registró el horario de la escuela que era de 9 de la mañana a 3 de la tarde. Además de los salones había un patio y un jardín, y si la escuela era rural, los ejercicios y los juegos se hacían en campo abierto, pues los alumnos salían de paseo todos los días, cuando el tiempo lo permitía. Observaba, como lo había indicado antes el profesor Alberto Correa, que la maestra del kindergarten era la parte más importante del sistema escolar pues solo disponía de tres horas diarias para contrarrestar la influencia de las otras veintiuna, en que el niño vivía quizá con gente ignorante o viciosa, por tanto había de escoger "maestras inteligentes e instruidas, de estricta moralidad y mucho juicio (y no) de paciencia aprobada y de abnegación" como las que había conocido hasta entonces (Méndez de Cuenca, 1905, p. 315).

La escuela estaba dotada de lavabos e inodoros y al interior del salón de clases había espacio para recibir entre 35 y 50 alumnos, quienes eran atendidos por una maestra que cuidaba la disciplina y repetía su explicación tantas veces como fuera necesario. Llamaba su atención que la escuela estuviera normada por reglas que se cumplían como la prohibición a los directores de dar clase o la presencia de ayudantes, solo debido a la ausencia de un profesor y cuando el Departamento de Instrucción Pública los requería pues las clases nunca se suspendían repentinamente porque los maestros no solían pedir licencias ni mandar excusas a última hora. La escuela se asentaba sobre la base del progreso individual como premisa del progreso colectivo; la responsabilidad individual era el cimiento de la responsabilidad común (Méndez de Cuenca, 1905).

Para la profesora Zapata era importante el que las futuras maestras de párvulos en México, tuvieran una educación completa como la que se ofrecía en Estados Unidos en los que se cursaban en dos años las materias de Psicología Moderna y su aplicación práctica a los métodos de educación, la naturaleza mental y física de los niños; la Teoría del Kindergarten, donde se estudiaban los principios de Froebel, sus dones y ocupaciones; el Estudio de la Naturaleza, dentro de un salón que parecía un jardín con las plantas que recolectaban en sus excursiones; Higiene y Fisiología, dedicado a los juegos, bailes, ejercicios físicos y respiratorios; Música, con canto coral, individual y ejecución en el piano de diversas piezas; la práctica, que 
incluía el ejercicio de los métodos de Pestalozzi y Froebel. En el primer año, visitaban algunos kindergarten y, en el segundo, elaboraban un programa original que las habilitaba para dirigir una clase.

Los requisitos de ingreso a estos estudios eran: contar con el título de maestra normalista o pasar un examen general con énfasis en literatura inglesa, historia general, geografía y geometría, además de contar buena salud, imaginación, voz, disposición para el piano y cariño por los niños. En cuanto al personal que impartía los cursos, se trataba de profesoras graduadas en alguna universidad o escuela normal.

En cuanto al método, la profesora Laura Méndez subrayó dos virtudes de la enseñanza en este nivel: el uso de los dones de Froebel y la calidad de las instalaciones. Su uso permitía que los niños jugando, jugando, aprendieran a formar sobre las mesas cuadriculadas, todos los caracteres del alfabeto, con barras de metal o de madera y argollas divididas en mitades, o en cuartos de círculo, que les ayudaban a nombrar los caracteres a simple vista distinguiendo por ejemplo la hache de la jota, la pe de la eme, exceptuando las letras $\tilde{n}$ y ch que no existían en el alfabeto inglés, usando diferentes imágenes de animales o al contar del uno al diez, calculando con precisión. Estos ejercicios preparaban para mejorar la caligrafía, que unida a una buena ortografía, "abre muchas puertas al hombre de negocios en los Estados Unidos". Esta enseñanza se complementaba en el jardín anexo, que ponía a los niños en contacto con la naturaleza. Si había que hacer una crítica al sistema norteamericano era en las lecciones de los libros de texto referentes a fiestas religiosas como la Navidad y el Día de Gracias a pesar del carácter laico de la legislación estadounidense (Méndez de Cuenca, 1905).

Al comparar la experiencia mexicana con el kindergarten estadounidense, la profesora Rosaura Zapata señaló la diferencia de contar con una sección de transición donde se iniciaba al niño en la lectura, escritura y aritmética, que no existía en el caso mexicano. La edad de ingreso era 3 años y ahí permanecían durante tres más. La enseñanza se realizaba con base en el procedimiento objetivo con imágenes y objetos. Dibujaban en la arena diversas letras y llamaba su atención el que aprendieran la aritmética de manera divertida por medio de juegos especiales. Le sorprendía la existencia de una inspectora de aseo, quien visitaba con frecuencia los establecimientos y regresaba a su casa a los alumnos desaseados.

Como vemos, la información que las profesoras dieron fue de diferente orden. En primer lugar, compartieron la experiencia de conocer un sistema educativo que era necesario en todo país que requería educar a sus ciudadanos de cualquier edad. Gracias a estas observaciones se hicieron evidentes las deficiencias y particularidades del sistema mexicano porque si bien existían "buenos libros de pedagogía [...] y tan cumplidos pedagogos (que) tienen en sus manos la instrucción pública" (Méndez de 
Cuenca, 1905, p. 240), eran los profesores viajeros quienes se ocuparían de subrayar una serie de detalles en los que poco se había reparado y que podían ser de utilidad para reformar el nivel de estudios ${ }^{7}$.

El viaje de la maestra Rosaura Zapata se inscribe en esta primera globalización que señala Matasci (2012), pues por varios años continuó en comunicación con algunas maestras estadounidenses quienes le enviaron información sobre otros métodos de enseñanza. Uno de estos fue el método de María Montessori, que proponía combinar con el de Froebel pues coincidían en la necesidad de la educación física como una actividad esencial del cuerpo por medio de ejercicios rítmicos, de manera graduada y fácil que llevaba a una mejor adquisición de saberes como la lectura, escritura y aritmética. Recomendable para resolver los problemas que tenía el niño mexicano, "entreverar los métodos Montessori y Froebel", pues en el sistema Montessori, las actividades se realizaban "en una atmósfera de libertad y disciplina natural". En la práctica, la función de la maestra era esencial porque de ella dependía de que los primeros valores de la vida del niño fueran el reflejo de su vida entera, por esta razón al tener una gran responsabilidad en las manos la respuesta era "estudiar con ahínco, moderar nuestras fuerzas y, si nos encontramos débiles para esta tarea, renunciar a este medio de subsistencia".

Los informes de las profesoras Zapata y Méndez mostraron el interés por desarrollar este aprendizaje en México. Se inició un proyecto más sólido con la fundación de dos escuelas en la Ciudad de México bajo la dirección de Estefanía Castañeda y Rosaura Zapata, donde planeaba poner en práctica lo aprendido durante su misión pedagógica, a saber:

los métodos que se siguen en los establecimientos de igual categoría en los Estados Unidos del Norte [...] respetuosamente pido se me deje en libertad de implantarlos en el kindergarten que estará a mi cargo, sin sujetarme a mas plan que a los que en la citada Nación se observan. (AHSEP, 1898-1945)

Entre 1904 y 1907 se inauguraron cinco escuelas más dirigidas por profesoras que habían realizado misiones pedagógicas ${ }^{8}$. Las escuelas llevaron el nombre de los pedagogos más reconocidos de la época, Froebel, Pestalozzi, Spencer, Rousseau y Rebsamen, y en estas ocuparon cargos como directoras y escritoras de libros de texto en los que divulgaron sus

7 Laura Méndez de Cuenca lo señalaba: "dicen que las comparaciones son odiosas, pero a mí, me es imposible formarme juicio de las cosas sin caer en lo odioso de la comparación" (1905, p. 207).

8 Se inauguraron diversas escuelas: en 1904, la escuela Froebel dirigida por Estefanía Castañeda; en 1904, Pestalozzi, por Rosaura Zapata; en 1906, Spencer, por Carmen Ramos y Rebsamen por Leonor López Arellano; en 1907, Rousseau, por Beatriz Pinzón y un Anexo al Colegio de la Paz (Vizcaínas), (Castañeda, 1980, p. 71 y AHSEP. Expediente de Rosaura Zapata). 
conocimientos y pusieron en práctica diversas estrategias para fortalecer la escuela en la comunidad ${ }^{9}$. En 1908, por ejemplo, a petición de la profesora Estefania Castañeda, se inauguró el primer Club de Madres en el Kindergarten Rébsamen cuyo objetivo era ampliar el contacto del hogar con la escuela (Castañeda, 1908). Se trataba de un nivel escolar en el que las profesoras iban cobrando visibilidad y ocupando espacios que abonarían a la feminización la profesión.

La aceptación de esta propuesta puede verse en el registro de inscripción en el nivel de kindergarten de la escuela anexa a la Escuela Normal de Profesoras que atendía a los niños de la ciudad de México. La matrícula muestra que si bien hay deserciones por lo menos el $50 \%$ de los inscritos asiste y presenta el examen correspondiente (véase la tabla 1).

Tabla 1.

Escuela de párvulos anexa a la normal de profesoras

\begin{tabular}{|c|c|c|c|c|c|c|c|c|c|}
\hline 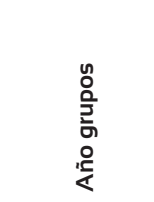 & 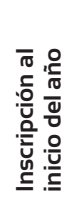 & 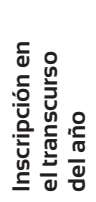 & $\begin{array}{l}\bar{\coprod} \\
\text { 。 }\end{array}$ & 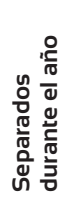 & 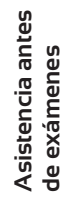 & 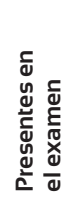 & 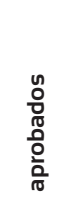 & 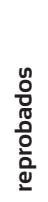 & 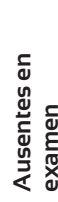 \\
\hline Grupo 1 & 80 & 5 & 85 & 43 & 42 & 20 & 29 & $\mathrm{O}$ & 13 \\
\hline Grupo 2 & 71 & 2 & 73 & 37 & 36 & 27 & 27 & O & 9 \\
\hline Grupo 3 & 75 & 4 & 79 & 36 & 43 & 35 & 35 & O & 8 \\
\hline Grupo 4 & 63 & 19 & 82 & 40 & 42 & 31 & 31 & O & 11 \\
\hline 20 -Grupo 1 & 62 & $\mathrm{O}$ & 62 & 8 & 54 & 47 & 47 & $\mathrm{O}$ & 7 \\
\hline Grupo 2 & 47 & $\mathrm{O}$ & 47 & 8 & 39 & 37 & 37 & $\mathrm{O}$ & 2 \\
\hline $3^{\circ}$ & 26 & O & 26 & O & 26 & 26 & 26 & $\mathrm{O}$ & $\mathrm{O}$ \\
\hline Total & 424 & 30 & 454 & 172 & 282 & 232 & 232 & $\mathrm{O}$ & 50 \\
\hline
\end{tabular}

Fuente: elaboración propia.

9 La Enseñanza Normal, que circuló los días 8 y 22 de cada mes, publicó en la sección "variedades", las lecciones traducidas del inglés al castellano de Rosaura Zapata, con las cuales conformó tiempo después un libro que editó bajo el sello editorial de la Casa Herrero Hermanos Sucesores, con el título de Cantos y juegos para el kindergarten (Castañeda, 1908). 


\section{Notas finales}

Con la práctica de las misiones pedagógicas, las profesoras aumentan sus espacios laborales con lo que se fortalece la idea de Hussaye (2006) sobre la importación pedagógica. Lo observamos en las fotografías que acompañan sus textos donde notamos que se van reduciendo aquellas que las muestran estáticas o en segundo plano por otras donde son las protagonistas de las notas. Los informes sobre sus viajes al extranjero, y sobre el kindergarten en particular, se acompañan de fotografías, como la siguiente que resulta excepcional porque podemos identificar diversos personajes: las inspectoras de la enseñanza Normal, Clementina Ostos; la inspectora médica Columba Rivera; Esther Huidobro, subdirectora de la escuela de Párvulos, anexa a la Normal, junto a profesores como Juan León, director de la Escuela Práctica Anexa a la Normal de Profesores. En esta fotografía también se muestra a dos profesores norteamericanos: miss Emma L. Johuston, directora de la Normal Fraining School for Teachers en Brooklyn, Nueva York, y el doctor Thomas M. Balliet, decano de la Escuela de Pedagogía de la Universidad de Nueva York ${ }^{10}$.

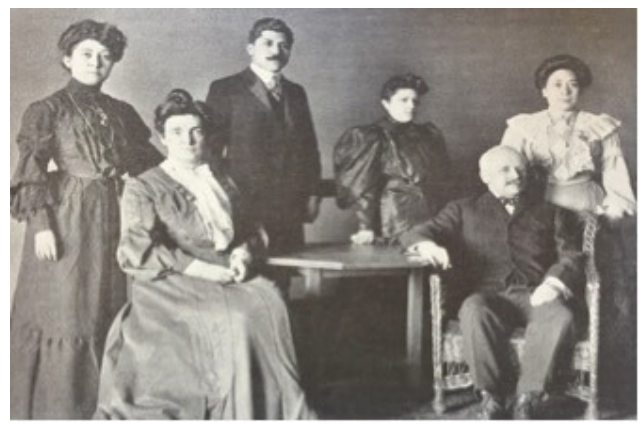

Figura 1. Maestras viajeras hacia los Estados Unidos Fuente: Ostos, La Enseñanza Normal (1904, p. 129).

Una imagen que fortalece la idea de que el modelo educativo norteamericano empezaba a ser un referente en México pero también que confirma que las mujeres ocupaban ya un espacio en el gremio. Por lo menos es lo que se percibe en la reflexión del profesor Leopoldo Kiel San Luis, Misuri, en 1904, cuestionaba uno de los rasgos característicos de

10 "A pesar de la aparente neutralidad del ojo de la cámara y de todo el verismo iconográfico, la fotografía será siempre una interpretación [...] no sustituye la realidad...apenas aporta informaciones visuales sobre un fragmento de lo real, seleccionado y organizado estética e ideológicamente [...] cabe al intérprete comprender la imagen fotográfica como información discontinua de la vida pasada, en la cual pretende sumergirse [...]" (Kossoy, 2001, p. 89). 
la escuela pública estadounidense, el de la feminización"11. "De tiempo atrás me ha preocupado mucho [...] la idea de que los norteamericanos han pensado que sus mujeres eran superiores. No pude antes de ahora, comprender esto, pero hoy si lo comprendo, ellas, lo son" (Ostos, La Enseñanza Normal, 1905, p. 45).

Otra observación tiene que ver con la variedad de los informes. Si bien las maestras viajeras hacían ver que se trataba de una enseñanza práctica $^{12}$, también hubo, como lo señala Matasci (2012), una representación idealizada de la educación del otro. En el que escribe Rosaura Zapata hay observaciones que aspiran a plantear cambios positivos para el caso mexicano. Pero más allá de esto, también existe un compromiso del viajero con el su grupo como lo declara otra viajera, la profesora Clementina Ostos, quien refiere en octubre de 1905:

Debemos decir con franqueza que vimos mucho y observamos mucho, que nos llenó de noble envidia y creemos que será conveniente que aquellos que hemos tenido el honor de ir al extranjero para observar lo bueno, vayamos soltando en nuestra carrera [...] sin prejuicios ni temores el bagaje recogido. (Ostos, 1905, p. 306)

Otra cuestión importante a señalar es que las revistas pedagógicas permitieron visibilizar la obra de las maestras viajeras, publicando sus informes pero también extractos de sus libros o la traducción de poemas e historietas que fue conformándose como una producción especialmente dedicada a los pequeños niños, en la que se daba cuenta del interés por este nivel escolar pero también un manejo de los contenidos y del idioma pues fueron traducidas del inglés, El gigante y la hada por Rosaura Zapata y la colección de cuentos, Guillermito y el Oriol por Berta von Glümer (Zapata y Von Glumer, 1905, p. 345).

11 Durante las exposiciones internacionales que tuvieron lugar en Estados Unidos se tuvo contacto con métodos, planes, programas, proyectos de atención a niños pobres, la arquitectura escolar y una serie de propuestas educativas implementadas en Alemania, Suiza, Inglaterra, Bélgica, Japón y otros. En Estados Unidos se desarrollaron cuatro exposiciones universales (Filadelfia 1876, Nueva Orleans 1884, Chicago 1893 y San Luis 1904). Los avances en la instrucción primaria de los Estados Unidos impresionaban no solamente a los viajeros mexicanos. El inspector francés Ferdinand Buisson, en su reporte sobre Filadelfia 1876 declaraba: "no es la obra de algunos filántropos o sociedades religiosas, es un servicio público por el que los Estados, las comunas y las villas inscriben en sus presupuestos ordinarios, una suma que ningún país del mundo pudiera imaginar destinada a la educación" (citado en Matasci, 2015, p. 48).

12 La directora de la Escuela Práctica Anexa a la Normal de Profesoras, Esther Huidobro de Azua señalaba su importancia: "Hoy que parece entrar en la Escuela de Párvulos en México en una era más prospera, vendrán, como consecuencia, la formación perfectamente graduada del nuevo profesorado y la aparición de trabajos literarios que no solamente sugieran ideas para ser desarrolladas [...] verdaderas enseñanzas prácticas que seguir para todas las profesoras, a fin de que las inteligencias no tengan que fatigarse en adquirir ideas a la vez que en crear aplicaciones de las mismas" (La Enseñanza Normal, 1904, p. 220). 
Después de su viaje por los Estados Unidos, la profesora Rosaura Zapata fortaleció su lugar dentro del magisterio. Para 1906, Zapata ya ocupaba un puesto como vocal de la mesa representante de las Directoras de Escuelas de Párvulos en la Academia de Profesoras y junto con otras profesoras, como Estefanía Castañeda, Laura Méndez de Cuenca, Berta von Glumer, que también habían viajado al extranjero para conocer sobre esta formación, se ocuparon de la dirección de las primeras escuelas de párvulos en la ciudad de México ${ }^{13}$.

Si bien los profesores mexicanos continuaron viajando hacia los Estados Unidos para conocer métodos, planes y programas de los diferentes niveles educativos, el intercambio y la curiosidad de los norteamericanos se dio hasta la década de los años treinta en que aumentaba la migración de mexicanos hacia el Norte. La profesora Katherine M. Cook, jefa de la Sección de Problemas Especiales de la Oficina de Educación del Departamento del Interior de los Estados Unidos, fue invitada a México para conocer cómo se atendía a la población rural con el proyecto de las Misiones Rurales:

muchos de estos niños mexicanos aprenden a hablar nuestro idioma, y son asimilados por nuestra vida social y política, únicamente a expensas de mucho tiempo y de grandes esfuerzos de parte de nuestras escuela. Estamos comenzando a comprobar que un amplio conocimiento del país y de los antecedentes culturales de estos niños, así como de su situación social en el hogar, conduce a un mejor entendimiento de sus necesidades y habilidades [...] particularmente estamos interesados en la rehabilitación económica y social de los nativos, cuyos orígenes, tradiciones y lenguaje son completamente diferentes. (1936, p. 12)

Este interés persiste hasta el día de hoy ${ }^{14}$.

13 Las primeras profesoras de párvulos que presentaron examen de oposición en la Dirección General de Educación Primaria y obtuvieron una plaza en 1905 fueron: Elena Zapata, Leonor López Arellano, Elisa Allande, Carolina Alcocer, Carmen Marroquín, Beatriz Pinzón y Carmen Ramos (Castañeda, 1980).

14 En este momento había cerca de seis millones de indios repartidos en más de cuarenta familias que hablaban entre cien lenguas y dialectos, además de los cuatro millones de mestizos que se encontraban en estado de precariedad y necesitaban ser incorporados a la civilización por medio de una cultura integral. Para "contrarrestar y anulados por el medio adulto, donde no se lee ni se escribe, ni se habla castellano, ni se tiene un ideal, ni se tiene una patria. Los niños y los adultos, toda la comunidad debe ser nuestra materia prima" (Sáenz, 1929). 


\section{Referencias}

Archivo Histórico de la Secretaría de Educación Pública, Sección Antiguo Magisterio, Expediente de la profesora Rosaura Zapata, 1898-1945

Academia de Profesores. (1907). Informe. La Escuela Mexicana, 20(6), 288.

Ayuntamiento de la ciudad de México. (1900). Informe. Revista de la Instrucción Pública Mexicana, 10(4), 300-304.

Barby, R., Simon, F. y Depaepe, M. (2016). Même absent, il était présent": Hilaire Delobel (1889-1958) como autor de manuales escolares. En L. Galvan, L. Martínez y O. López (Coords.), Más allá del texto: Autores, redes del saber y formación de lectores (pp. 401-433). Ciesas; UAEM; Colegio de San Luis.

Bazant, M. (2003). Una visión educativa contrastada: La óptica de Laura Méndez de Cuenca, 1870-1910. Revista Mexicana de Investigación Educativa, 8(18), 503-546.

Bazant, M. (2013). Una musa de la modernidad: Laura Méndez de Cuenca (1853-1928). Historia de la Educación Latinoamericana, 15(21), 19-50.

Braster, S. y Del Pozo, A. (2018). Entrevista, Frank Simon: A personal story about everyday educational realities. Historia y Memoria de la Educación, 8, 739-777.

Canales, P. (2019). Entre Malthus y Darwin: Modelos y ausencia de correlación entre producción alimentaria y crisis demográfica (Valle de Toluca, 1654-1815). En C. Cramausel (Eds.), La incidencia demográfica de crisis de subsistencia, escasez y epidemias: Comparaciones entre el viejo mundo y el nuevo mundo (pp. 109-153). El Colegio de Michoacán, Universidad Autónoma del Estado de Morelos.

Castañeda, E. (1908). El kindergarten. La Escuela Mexicana, 28(5), 288.

Castañeda, E. (1980). Manuales del kindergarten en conexión con el primer ciclo de la escuela primaria. Filosofía, historia, leyes, organización, propósitos, planes de estudio, normales y técnicas del kindergarten. Universidad Autónoma de Tamaulipas-Editorial Jus [Publicado originalmente en 1906].

Cook K. M. (1936) La Casa del pueblo. Un relato acerca de las escuelas nuevas de acción de México. Secretaría de Educación Pública.

Estado de Jalisco (1900). Programa de estudios de kindergarten en el Estado. Revista de la Instrucción Pública Mexicana, 20(4), 407.

Estado de Morelos (1900). Programa de estudios de Kidergarten en el Estado. Revista de la Instrucción Pública Mexicana, 26(4), 471.

Galván, L. (1991). Soledad compartida: Una historia de maestros. Ciesas.

Galván, L., Frank, S. y Federico L. (Coords.). (2014). Poder, fe y pedagogía: Historias de maestras mexicanas y belgas. UAM-Iztapalapa. 
Kossoy, B. (2001). Fotografía e historia. Biblioteca de la Mirada.

Matasci, D. (2012). Jalons pour une histoire de la circulation internationale du "modxle scolaire" suisse a la fin du xix eme siecle. Itinera, 32, 177-190.

Matasci, D. (2015). L'école republicaine et l'étranger. Une histoire internationale des réformes scolaires en France 1870-1914. ENs Editions.

Méndez de Cuenca, L. (1905). Informe. La Escuela Mexicana, 1(2), 20, 139 y 176.

Méndez de Cuenca, L. (1905). Informe. La Escuela Mexicana, 27(2), 240.

Méndez de Cuenca, L. (1905) Informe. La Escuela Mexicana, 36(2), 315 y 317.

Moreno, P. (2007). Por las escuelas de Europa: los viajes de Félix Martí Alpera (1900-1911). En A. Venancio y J. Goncalves (Orgs.), Viagens pedagógicas (pp. 114-143). Cortez Editora.

Ostos, C. (1905). Informe. La Enseñanza Normal, 20(5), 306.

Rogers, R. (2008). Notes Critiques a propos de Houssaye Jean (dir.) Femmes pedagogues, t.1: De l'Antiquité aux xIx eme siecle. Paris, Ed. Fabert, 2008. Revue Histoire de l'Education. 98, 5-37.

Velázquez, M. (1905). La enseñanza de la educación física en Suiza. La Escuela Mexicana, 40(2), 458 y 484.

Viñao, A. (2007). Viajes que educan. En V. Mignot, A. Crystina y J. Goncalves. (Org.), Viagens pedagógicas (pp. 15-39). Cortez Editora.

Zapata R. y Von Glumer B. (1905). Cuentos infantiles. La Escuela Mexicana, $32(2), 345$.

Zapata, R. (1908). Informe sobre el kindergarten en Estados Unidos. La Enseñanza Normal, 12(8), 125. 